\title{
Response to the letter to the editor entitled "Forty-two-month outcome of intravitreal bevacizumab in myopic choroidal neovascularization"
}

\author{
Gian Marco Tosi ${ }^{1} \cdot$ Claudio Traversi $^{1} \cdot$ Elisabetta Nuti $^{1} \cdot$ Davide Marigliani $^{1}$
}

Received: 26 August 2015 / Accepted: 28 August 2015 /Published online: 10 September 2015

(C) Springer-Verlag Berlin Heidelberg 2015

Dear Editor,

We thank Chew and Tan for their interest in our recent article in Graefe's Archive for Clinical and Experimental Ophthalmology [1].

With regard to extrafoveal myopic choroidal neovascularization (mCNV), we agree with Chew and Tan about a continuing role for photodynamic therapy in this patient category [2]. Our population was composed of subfoveal and juxtafoveal mCNV. In our opinion, for such mCNV locations the treatment of choice is anti-VEGF therapy. However, anti-VEGF therapy should be offered paying close attention to the ocular and systemic side-effects, bearing in mind that the clinical trials for anti-VEGF were not focused primarily on safety [3].

A limitation of our study was the lack of evaluation of any OCT changes [1]. We agree with Chew and Tan that important additional information could have been provided by such an evaluation. For this reason, in successive patients we decided, as suggested by Chew and Tan, to perform the analysis of CMT differences after adding $60 \mu \mathrm{m}$ to the CMT values measured by the Stratus OCT [4].

Swept-source OCT could certainly add to our "anatomical knowledge" [5].

Gian Marco Tosi

gmtosi@tin.it

1 Ophthalmology Unit of the Department of Medicine, Surgery and Neuroscience, University of Siena, Viale Bracci 1, 53100 Siena, Italy
Acknowledgments None of the authors have a proprietary interest.

\section{References}

1. Traversi C, Nuti E, Marigliani D, Cevenini G, Balestrazzi A, Martone G, Caporossi T, Tosi GM (2015) Forty-two-month outcome of intravitreal bevacizumab in myopic choroidal neovascularization. Graefes Arch Clin Exp Ophthalmol 253:511-517

2. Tan CS, Chew MC, Lim TH (2014) Comparison of foveal-sparing with foveal-involving photodynamic therapy for myopic choroidal neovascularization. Eye (Lond) 28:17-22

3. Schmidt-Erfurth U, Chong V, Loewenstein A, Larsen M, Souied E, Schlingemann R, Eldem B, Monés J, Richard G, Bandello F; European Society of Retina Specialists (2014) Guidelines for the management of neovascular age-related macular degeneration by the European Society of Retina Specialists (EURETINA). Br J Ophthalmol 98:1144-1167

4. Kakinoki M, Sawada O, Sawada T, Kawamura H, Ohji M (2009) Comparison of macular thickness between Cirrus HD-OCT and Stratus OCT. Ophthalmic Surg Lasers Imaging 40:135-140

5. Tan CS, Ngo WK, Cheong KX (2015) Comparison of choroidal thicknesses using swept source and spectral domain optical coherence tomography in diseased and normal eyes. Br J Ophthalmol 99: $354-358$ 